\title{
Efficacy Study of Chloroquine to Plasmodium vivax Malaria in Darimu and Bure Districts, Southwest Ethiopia
}

\author{
Solomon Yeshanew (1D) \\ Alemayehu Dagne ${ }^{2}$ \\ Behailu Taye ${ }^{2}$ \\ 'Department of Biology, Debre Markos \\ University, Debre Markos, Ethiopia; \\ ${ }^{2}$ Department of Biology, Mettu \\ University, Mettu, Ethiopia
}

This article was published in the following Dove Press journal: Infection and Drug Resistance

Background: Chloroquine (CQ) is the first line treatment for vivax malaria in Ethiopia. However, the therapeutic efficacy of the drug is now declining. Several reports from different areas of the country showed CQ-vivax treatment failure increasing. This study therefore aimed to provide additional data on the therapeutic efficacy of CQ against Plasmodium vivax malaria from two districts of Southwestern Ethiopia.

Methods: An observational prospective study among $P$. vivax malaria infected individuals was conducted in two districts of Southwest Ethiopia for a period of 28 follow-up days. Study participants were treated with $25 \mathrm{mg} / \mathrm{kg}$ of standard CQ for 3 consecutive days according to the procedure. Microscopic blood film examinations and other clinical assessments were measured within the follow-up period on a weekly basis.

Results: A total of 115 patients were enrolled in the study. Sixty-five were from Darimu and 50 were from Bure districts. The majority (67\%) of study participants were male and $86.1 \%$ (99/115) were below 35 years old. The study revealed that CQ treatment was able to clear vivax malaria parasites and febrile within a week. During the follow-up study period, recurrence of vivax parasitemia was not recorded. However, there was a marked heterogeneity with respect to fever clearance time, parasitemia load, and carriage of parasite gametocyte within 72 hours of post-treatment between the two study areas.

Conclusion: The present study revealed that CQ has good clinical and parasitological response to vivax malaria in the study areas. Thus, it can be continued as the first line $P$. vivax malaria treatment. However, further monitoring and evaluation of the drug should be considered.

Keywords: Chloroquine, In vivo, P. vivax, Southwest Ethiopia, Treatment failure

\section{Introduction}

The malaria diseases caused by $P$. falciparum and $P$. vivax parasites are still the number one public health problems worldwide, and approximately $90 \%$ of the disease burden and death are found in sub-Sahara African countries. ${ }^{1}$ Globally an estimated 207 million people become infected each year, with around 627,000 deaths being reported. However, now encouraging reports show the rate of morbidity and mortality are declining. ${ }^{2}$

The emergence of antimalarial drug resistant Plasmodium parasites hampered the management and control of the disease. . falciparum, which causes the most severe form of malaria, developed resistance against all the currently available antimalarial drugs including the artemisinin derivatives, while CQ resistance was
Correspondence: Solomon Yeshanew Tel +25l-9l3-936-754

Email solarm12@yahoo.com
Infection and Drug Resistance 2021:14 795-803 
reported in 1998. ${ }^{3,4}$ However, in many parts of the world, CQ remains the first-line treatment for $P$. vivax malaria and the emergence of resistance is now compromising its use. $^{5,6}$

P. vivax is a major cause of morbidity, causing more than 72 million clinical cases of malaria disease worldwide each year. ${ }^{7}$ Vivax malaria is an important cause of morbidity, especially in young children, with adverse consequences for education, development, and comfort. ${ }^{8,9}$ In Ethiopia, it is the second most important Plasmodium parasite, accounting for more than $35 \%$ of the malaria cases and most recently the proportion is increasing.$^{10-12}$

CQ and Primaquine (PQ) are first-line treatments used for Vivax malaria infections, where the latter is the only one effective in clearing the hypnozoite stage of the parasite. $^{13}$ Since 1989 , CQ-resistance to $P$. vivax has continued to occur in different regions at varying degrees and now it has already reached an alarming prevalence. ${ }^{4} \mathrm{CQ}$ is the cheapest and mainstay treatment for vivax malaria in Ethiopia. A few reports have shown its efficacy is declining. Reports by Hiwot et al in Debrezeit, with a $4.6 \%$ rate of treatment failure, Tsige et al in Jimma zone, with $3.6 \%$, and more recently Zewde et al and Assefa et al in Jimma and Hossana towns reported $2.7 \%$ and $3.3 \%$ treatment failures, respectively, are baseline evidence that $P$. vivax resistance to $\mathrm{CQ}$ is increasing in the country. ${ }^{14-17}$

In Bure and Darimu districts, despite being among the most malarious areas in Southwest Ethiopia, an efficacy study of antimalarial drugs has not yet been reported. Therefore, the present study aimed to determine the therapeutic efficacy of standard CQ against $P$. vivax malaria in an open one arm observational-prospective follow-up study in patients who presented to the outpatient departments of four selected health centers in the districts.

\section{Materials and Methods}

\section{Study Areas}

The study was conducted between March and December, 2018 at four sites of Darimu and Bure districts of the Southwestern part of Ethiopia (Figure 1). They are located around 650 and $680 \mathrm{~km}$, respectively, from the capital, Addis Ababa, in Ilubabore administrative zone. Darimu district is found at the altitude range between 1,700$1,900 \mathrm{~m}$ above sea level, whereas Bure district is found at the altitude range of 1,300-1,646 $\mathrm{m}$ above sea level. These areas are typically characterized by having the average annual rainfall of 1,500-2,000 $\mathrm{mm}$ within the last 10 years (2006-2016). During the same period, the minimum and maximum temperatures of the areas were $18.5^{\circ} \mathrm{C}$ and $31^{\circ} \mathrm{C}$ for the former and $12.5^{\circ} \mathrm{C}$ and $27^{\circ} \mathrm{C}$ for the latter districts, respectively (National Meteorology Agency, Annual Bulletin, 2016).

In these districts, both $P$. falciparum and $P$. vivax malaria parasites are found predominantly and account for $45 \%$ and $55 \%$, respectively. The annual number of vivax malaria cases in the study districts varies on the bases of location and season. However, an average of $4250 P$. vivax confirmed positive cases were reported in 2016 (Zonal Health Office Report, 2017). Because malaria transmission is seasonal in Ethiopia, the high transmission peaks are usually recorded in the months of September to December and April to June of each year. ${ }^{10}$ In the study areas, vivax malaria recurrence pattern and CQ treatment failure have not yet been reported.

\section{Study Design}

We have used a one-arm prospective, observational follow-up study design for evaluation of the clinical and parasitological responses of the directly observed CQ treatment of uncomplicated $P$. vivax malaria from September to January, 2018, Southwest Ethiopia.

\section{Patient Recruitment and Inclusion Criteria}

Patients who were attending the outpatient clinics of each health center were screened for the study that fulfills the following criteria: a) age $>6$ months; b) $P$. vivax mono-infection with parasitemia $>250 \mathrm{ap} / \mu \mathrm{L} ; \mathrm{c}$ ) an axillary temperature of $\geq 37.5^{\circ} \mathrm{C}$ or history of fever within 48 hours; d) the ability to swallow oral CQ medication; e) residence in close proximity to the health centers; and f) willingness to participate in the study and be followed-up for 28 days. However, patients with signs of severe or complicated symptoms of vivax malaria such as coma, impaired consciousness, respiratory distress, convulsions, mixed Plasmodium species, severe malnutrition, fever due to concomitant diseases, prior antimalarial intake within 2 weeks prior to enrollment, pregnant women, and those with a history of allergic reaction to CQ were excluded from the study. ${ }^{18}$

\section{Drug Treatment Procedures}

Commercially available standard $250 \mathrm{mg}$ chloroquinephosphate was used for treatment and $25 \mathrm{mg} / \mathrm{kg}$ of the drug was administered orally under direct supervision of 


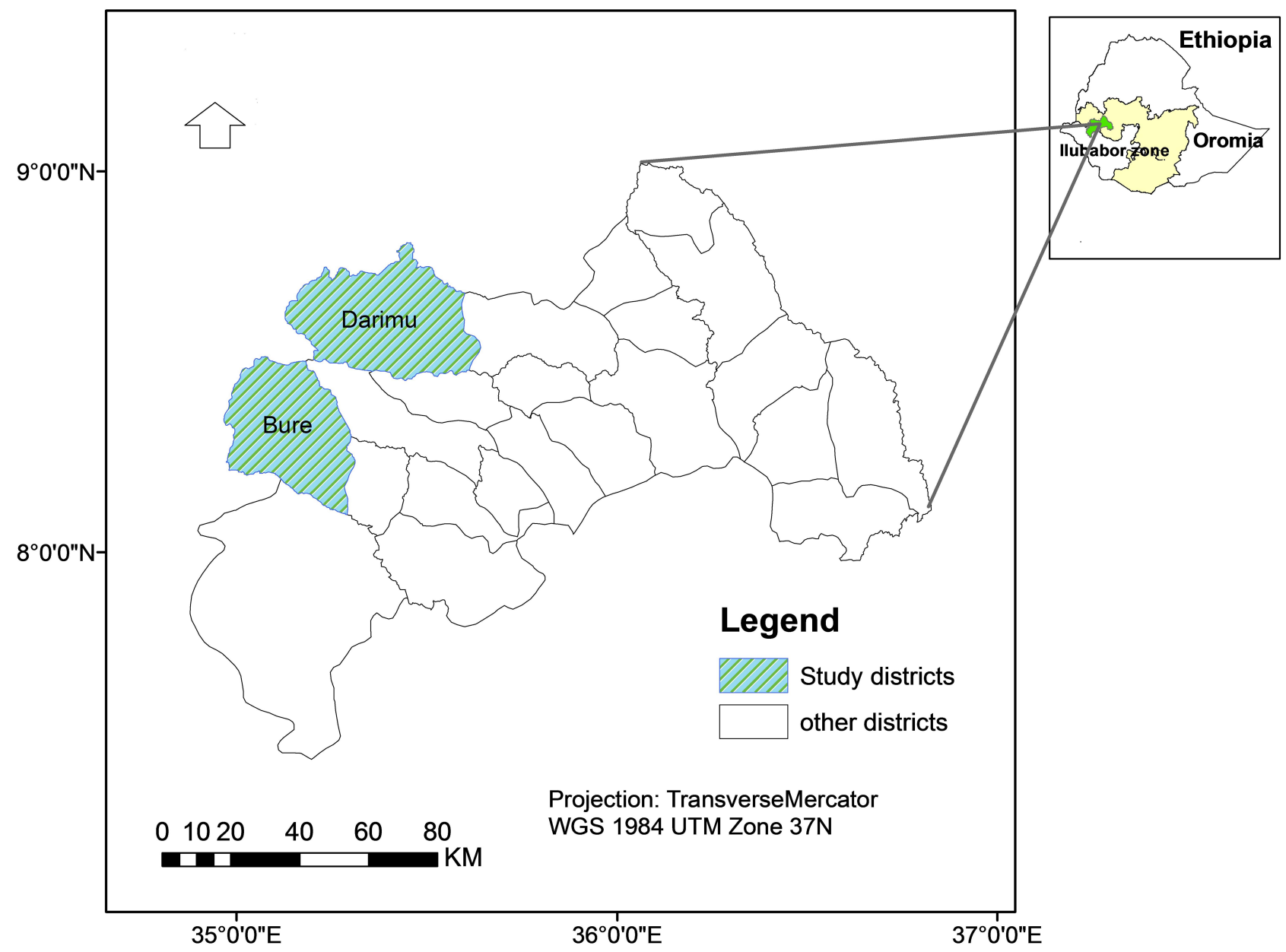

Figure I Geographical location of Darimu and Bure districts, Southwest Ethiopia.

clinical professionals for all patients identified with $P$. vivax positive individuals for 3 consecutive days using $10 \mathrm{mg} / \mathrm{kg}$ at days 0 and 1 and $5 \mathrm{mg} / \mathrm{kg}$ at day 2 according to the WHO guideline for the treatment of malaria. ${ }^{14}$ Patients who vomited within 30 minutes posttreatment were re-subjected to the same dose of drug. However, those who vomited twice were excluded from the study. According to the current national treatment guidelines recommendation, treatment of $P$. vivax using primaquine is applied in malaria elimination targeted districts only. ${ }^{19}$ Because these two study sites are not targeted areas, no primaquine was given.

\section{In vivo Study}

An In vivo drug efficacy follow-up study for a period of 28 days was carried out according to WHO guidelines for surveillance of antimalarial drug efficacy manuals. Patients enrolled in the study were informed to return for a follow-up on days 3, 7, 14, and 28 for clinical examinations of axillary temperature, malaria like illness, parasites in $\mathrm{RBC}$, and reoccurrence of the infection within the study period. ${ }^{18}$

\section{Operational Definitions}

Treatment success is defined as clearance of parasitemia with no reappearance in 28 follow-up days, whereas treatment failure is the relapse of parasitemia in the presence of CQ drug within the follow-up period. ${ }^{20}$

\section{Clinical Procedures}

General physical examination was conducted at the enrollment visit and baseline data such as age, sex, weight, and temperature were recorded. A finger prick blood sample was taken for microscopy parasite identification and parasitemia density at every follow-up visit. Hemoglobin $(\mathrm{Hg})$ was measured on the day of enrolment and on day 28. 


\section{Microscopic Examinations}

Duplicate thick and thin blood smear were prepared for each enrolled individual at any scheduled visit. The blood smears were then stained with $10 \%$ Giemsa, and diagnosis and density of the parasite were then done using light microscopy. In this procedure, two laboratory technologists read the microscopic fields and whenever there were discordance between the two regarding parasite species identification, a third professional read and confirmation was finally taken. For parasite density, the average of the two reads was taken as a closest count.

\section{Hemoglobin Level Determination}

To see the level of hemoglobin concentration before and after CQ treatment, Hg level tests were conducted according to the standard procedure; one drop of blood was applied on a Hemocue (Angelholm Sweden) rapid test kit on day 0 and on day 28. Finally, comparisons over time were performed to determine CQ effectiveness in preventing anemia.

\section{Sample Size Determination}

The sample size for the study, calculated based on the previous reports of $P$. vivax treatment failures to $\mathrm{CQ}$, was $3.6 \%$ in Serbo town, Jimma zone, Southwest Ethiopia, with a precision of $5 \%$ and a $5 \%$ significance level using the formula, $\mathrm{N}=(\mathrm{Z} / \mathrm{d}) 2 * \mathrm{P}(1-\mathrm{P}) .{ }^{21}$ Assuming a loss-to-follow up rate of $20 \%$ over a 28 -day study, 64 study participants from each district with a total of 128 individuals were planned to enroll for the study. However, at the mid and end of the study period, 13 study participants were absent from the follow-up and a total of 115 study participants completed the study.

\section{Ethical Issues}

The study was conducted in accordance with good clinical practices following the principle of the declaration of Helsinki. ${ }^{22}$ The study received ethical clearance endorsement from the Research, Ethical and Technical Clearance Committee of the College of Public Health and Medical Sciences, Mettu University. Formal Consent was also prepared and signed by individuals who participated in the study after detailed explanation of the study. For study participants below the age of 18 years, consent was given by their parent or guardian.

\section{Statistical Analysis}

Raw data were double entered into an Excel spreadsheet and then all statistical analyses were performed using SPSS version 20 software (IBM Corp. 2011). KaplanMeier survival probability analysis was carried out to evaluate the treatment outcome of study participants during a 28 days follow-up period. Student's $t$-test was also conducted to compare the changes in body weight, $\mathrm{Hg}$ level, and body temperature between $\mathrm{D}_{0}$ and $\mathrm{D}_{28}$. Finally, the Pearson's correlation test was conducted to see the relationship between treatment response and the outcome variables.

\section{Results}

\section{Characteristics of Study Participants}

A total of 115 P. vivax positive individuals completed the 28 days follow-up study period. Sixty-five participants enrolled in the study were from Darimu and the rest from Bure districts. Data collected from only these individuals were included in the analysis. Seventy-seven (67\%) of the study participants were male and the mean age in the former district was 21.3 years and 26.7 years in the latter district. The majority (86.1\%) of the study participants were below the age of 35 years old. Ninety-nine (86.1\%) had a history of fever and the same number had documented records at the first day of enrollment. The geometric mean parasite density at day zero $\left(D_{0}\right)$ in Darimu and Bure districts were $6,024.5$ parasites $/ \mu \mathrm{L}$ and 11,316 parasites $/ \mu \mathrm{L}$, respectively (Table 1 ).

Significant heterogeneity with respect to body temperature $\left(37-40^{\circ} \mathrm{C}\right)$, fever clearance time $(2.6 \%$ had fever at day 7$)$, and parasite density $(5,971-11,728)$ were recorded (Table 2) between the two sites. Body weight and $\mathrm{Hg}$ concentrations of patients were also performed and the result was foundto be markedly heterogenic too. The mean body weight and $\mathrm{Hg}$ level were 43.1 (12-75) $\mathrm{kg}$ and 11.1 (7-16) at Darimu district, and 53.9 (14-72) kgand $11.7(6-15)$ at Bure district respectively (Table 1). Furthermore, 59.1\% (68/115) of the study participants were identified with gametocyte carriage during the first day of diagnosis. However, after treatment with CQ, the carriages had disappeared at the fourth day of follow-up.

\section{Parasite Clearance}

Because of the fast-acting blood schizonticide nature of $\mathrm{CQ}$, fever clearance was achieved at day $3\left(\mathrm{D}_{3}\right)$ posttreatment among $61.7 \%(71 / 115)$ of study participants. 


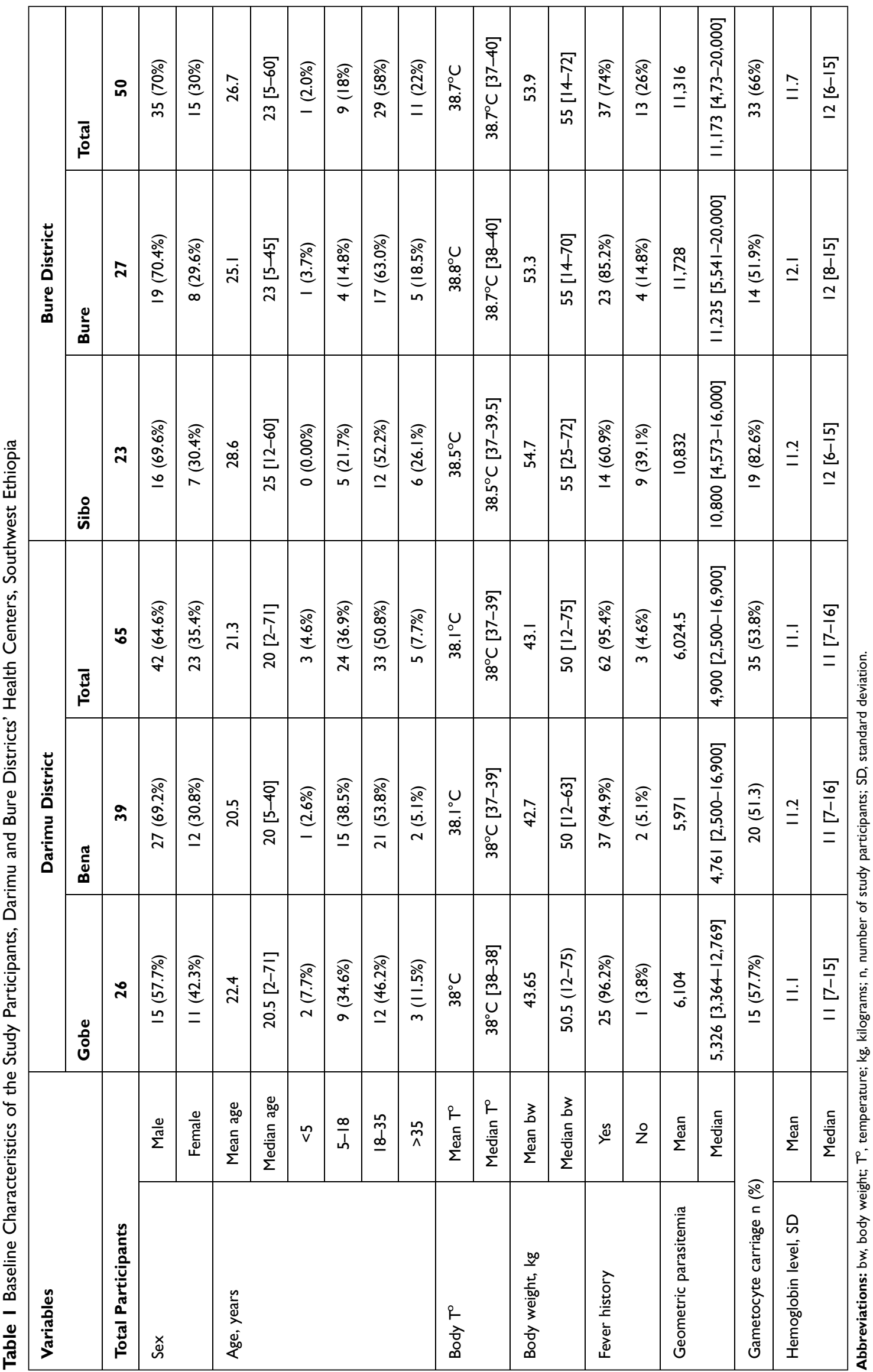


Table 2 Parasite and Fever Clearance Rate and $\mathrm{Hg}$ and Body Weight Recovery in the Study Participants, Bure and Darimu Districts, Southwest Ethiopia

\begin{tabular}{|c|c|c|c|c|c|c|}
\hline \multirow[t]{2}{*}{ Variables } & \multicolumn{5}{|c|}{ Follow-Up Periods } & \multirow[t]{2}{*}{ p-value } \\
\hline & $\mathbf{D}_{0}$ & $\mathbf{D}_{3}$ & $\mathbf{D}_{7}$ & $D_{14}$ & $\mathbf{D}_{\mathbf{2 8}}$ & \\
\hline \multicolumn{7}{|l|}{ A) Darimu District } \\
\hline Fever history & $62(95.4 \%)$ & $16(24.6 \%)$ & $2(3.1 \%)$ & $0(0.0 \%)$ & $0(0.0 \%)$ & 0.42 \\
\hline Geometric parasitemia & $6,024.5 \pm 381.5$ & $512 \pm 10.6$ & $0.36 \pm 0.10$ & $0.0 \pm 0.00$ & $0.0 \pm 0.00$ & 0.001 \\
\hline Hemoglobin level, g/dL & $I I .1 \pm 0.23$ & $t$ & $t$ & $t$ & $12.9 \pm 0.18$ & 0.36 \\
\hline Body temperature, ${ }^{\circ} \mathrm{C}$ & $38.1 \pm 0.04$ & $t$ & $\dagger$ & $t$ & $37.2 \pm 0.03$ & 0.27 \\
\hline Body weight, kg & $43.1 \pm 2.12$ & $t$ & $\dagger$ & $t$ & $43.3 \pm 2.1$ & 0.98 \\
\hline \multicolumn{7}{|l|}{ B) Bure District } \\
\hline Fever history & 37 (56.9\%) & $12(18.5 \%)$ & I (I.5\%) & $0(0.0 \%)$ & $0(0.0 \%)$ & 0.60 \\
\hline Geometric parasitemia & $|I, 3| 6.1 \pm 489.8$ & $405.2 \pm 13.8$ & $0.64 \pm 0.34$ & $0.0 \pm 0.00$ & $0.0 \pm 0.00$ & 0.02 \\
\hline Hemoglobin level, g/dL & $11.7 \pm 0.32$ & $t$ & $t$ & $\dagger$ & $|3.0 \pm 0.2|$ & 0.11 \\
\hline Body temperature, ${ }^{\circ} \mathrm{C}$ & $38.7 \pm 0.10$ & $t$ & $t$ & 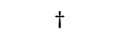 & $37.4 \pm 0.05$ & 0.12 \\
\hline Body weight, kg & $54.0 \pm 1.6$ & $t$ & $t$ & $t$ & $54.5 \pm 1.52$ & 0.55 \\
\hline
\end{tabular}

Note: ${ }^{\dagger}$ Not done.

Abbreviations: $\mathrm{D}_{0}$, Day zero; $\mathrm{g} / \mathrm{dL}$, gram per deciliter; kg, kilograms; ${ }^{\circ} \mathrm{C}$, degrees Celsius.

Similarly, parasite clearance from the patients were also successful on the same day of follow-up, with the clearance rate at Darimu district being $75.4 \%$ (49/ $65)$ and $76 \%(38 / 50)$ at Bure district. Complete parasitemia, fever, and gametocyte carriage clearances were realized on day $7\left(\mathrm{D}_{7}\right)$ of all cases, although insignificant positive RBS from slide films were detected (Table 2). In this study, at the end of the follow-up at 28 days, no recurrence of fever or detection of vivax parasitemia were recorded. Consequently, because of the absence of CQ-vivax treatment failure in the present finding, CQ-DCQ concentration assessment was not performed.

\section{Hemoglobin and Body Weight Measurements}

According to Table 2, the mean body weight and $\mathrm{Hg}$ at the baseline data were $43.1 \pm 2.12 \mathrm{~kg}$ and $11.1 \pm 0.23 \mathrm{~g} / \mathrm{dL}$ at Darimu, whereas they were $54.0 \pm 1.6 \mathrm{~kg}$ and $11.7 \pm 0.32$ $\mathrm{g} / \mathrm{dL}$ at Bure district, respectively. At the end of the follow-up $\left(\mathrm{D}_{28}\right)$ study period, the value of both parameters improved and was found to be $43.3 \pm 2.1 \mathrm{~kg}$ and $12.9 \pm 0.18$ $\mathrm{g} / \mathrm{dL}$ at Darimu and $54.5 \pm 1.52 \mathrm{~kg}$ and $13.0 \pm 0.21 \mathrm{~g} / \mathrm{dL}$ at Bure district, respectively. However, the changes were slight and insignificant.

\section{Discussion}

Due to the high spread of multidrug resistant malaria parasites, the control of the disease is becoming complicated. Thus, one of the approaches being instigated is provision of timely and effective antimalarial treatments to infected individuals with appropriate doses. Monitoring the dynamics of these antimalarial drugs therefore could help early identification of the resistant strains of the parasite and provide alternative measures. This observational follow-up study hence tried to assess the therapeutic efficacy of CQ against $P$. vivax malaria parasite in the study areas.

According to the WHO guideline for Monitoring antimalarial drug resistance protocol published in 2002, resistance can be defined as the presentation of signs of severe malaria illness within the first 2 days after supervised treatment or the presence of parasitemia and fever (axillary temperature $>37.5^{\circ} \mathrm{C}$ ) on any day between $\mathrm{D}_{7}$ and $\mathrm{D}_{28}$, irrespective of the clinical manifestation the patient presents. ${ }^{20}$ Or, the relapse of the parasite either from the liver or blood stage with the presence of minimal CQ-DCQ concentration in the blood. ${ }^{23}$ The present report, therefore, is in agreement with the definition and conveyed evidence for the absence of CQvivax treatment failure within the follow-up study period among study participants from both districts of the southwestern Ethiopia. 
Table 3 Pearson's Correlation Test Between Treatment Response and Parasitemia Clearance at the 28th Day

\begin{tabular}{|l|l|l|l|l|l|}
\hline \multicolumn{4}{|c|}{ Darimu District } & \multicolumn{3}{c|}{ Bure District } \\
\hline Treatment Responses & Pearson's Correlation & $P$-value & Treatment Responses & Pearson's Correlation & P-value \\
\hline Geometric parasitemia & 1.000 & $\dagger$ & Geometric parasitemia & 1.000 & $\dagger$ \\
\hline Body temperature & 0.300 & 0.008 & Body temperature & 0.280 & 0.051 \\
\hline Body weight & -0.400 & $<0.001$ & Body weight & 0.990 & $<0.001$ \\
\hline Hemoglobin level & -0.330 & 0.004 & Hemoglobin level & 0.497 & $<0.001$ \\
\hline
\end{tabular}

Note: ${ }^{\dagger}$ Not done.

At the first day of enrollment, $86.1 \%$ (99/115) of patients were febrile and $71.7 \%$ (71/99) of them were cleared within 72 hours. However, $100 \%$ clearances were achieved within a week of the follow-up observation period. Similarly, vivax parasitemia was cleared at the rate of $91.5 \%(6,024 \mathrm{para} / \mu \mathrm{L}$ to $512 \mathrm{para} / \mu \mathrm{L})$ at Darimu and $96.4 \%(11,316 \mathrm{para} / \mu \mathrm{L}$ to 405 para/ $\mu \mathrm{L}$ ) at Bure districts on $\mathrm{D}_{3}$ of post-treatment. However, $100 \%$ parasite clearances were attained on the seventh day $\left(D_{7}\right)$ post-treatment. Delayed fever and parasitemia clearance $(<95 \%)$ within 3 days of treatment is a predictor for parasite recrudescence and a useful marker for CQ resistance. ${ }^{3}$ The finding of the present study is inconsistent with previous reports in Ethiopia. The report by Teka et al ${ }^{14}$ in Debre Zeit showed the parasite clearance rate was $98 \%$ on $\mathrm{D}_{3}$, whereas Ketema et $\mathrm{al}^{15}$ from Serbo, Jimma zone reported $88 \%$ and $89.7 \%$ rates of parasite and fever clearance, respectively. However, the report by Zema et $\mathrm{al}^{16}$, from Jimma town and Getachew et $\mathrm{al}^{24}$ from southern Ethiopia had similar findings with the present study, excluding the insignificant number of patients who did not clear at $\mathrm{D}_{3}$ post-treatment. Both parameters then became cleared completely after the seventh day of treatment.

Anemia is one of the few outcomes of malaria illness and prompt treatments with appropriate antimalarial drugs are expected to improve the level of $\mathrm{Hg}$ over time. In this study, although the mean $\mathrm{Hg}$ level of the study participants were improved, the changes recorded were not statistically significant. However, the $\mathrm{Hg}$ level of a few enrolled patients did not recover, even at $\mathrm{D}_{28}$, which suggests that still at the end of the follow-up date, the presence of undetectable parasitemia in their blood after CQ treatment has completed. Similar findings by Ketema et $\mathrm{al}^{15}$ in Serbo, Jimma zone also came up with the same phenomenon where patients with recurrent parasites, were unable to recover their $\mathrm{Hg}$ level at the end of the study.
In the present study (Table 3), Pearson's correlation test was carried out in order to answer the question, does parasite clearance play a significant role in removing fever, improving body weight and $\mathrm{Hg}$ level among CQ treated vivax malaria infected patients? Hence, a significant correlation between parasite clearance and fever removal (axillary temperature $<37.5^{\circ} \mathrm{C}$ ) (Pearson correlation, $\mathrm{r}=0.300, P=0.008)$ at Darimu and (Pearson correlation $\mathrm{r}=0.280, P=0.051)$ at Bure districts was recorded. This may indicate that fever exclusively depends on the parasite load. The finding of this study was then found to be in contrast with the report of Zema et al ${ }^{16}$ where fever was not entirely dependent on parasite load, rather individual variation of body response to the parasite was suggested. Similarly, the correlation test between parasite clearance and $\mathrm{Hg}$ level improvement was also found to be significant (Pearson correlation $\mathrm{r}=0.330, P=0.004$ ) which again suggests that the majority of the study participants were not found to be anemic at the end of the follow-up 28 days.

Although several reports from different areas of the country denote the emergence of CQ resistant $P$. vivax malaria parasites, the present study revealed evidence of CQ can still be used as the main stay treatment for vivax malaria in the study areas. However, there were significant records of high parasite density, long fever clearance time, and unrecovered $\mathrm{Hg}$ being indications of the risk of developing CQ-vivax treatment failure in the near future in the areas.

\section{Conclusion}

The present study revealed good clinical and parasitological response of CQ to $P$. vivax. Fast clearance of parasitemia and fever was recorded within a week and absence of infection recurrence within the follow-up 28 days could justify the drug can be continued as the first line $P$. vivax malaria treatment in the study areas. However, there is a 
need of further regular monitoring and evaluation of the drug.

\section{Abbreviations}

CQ, chloroquine; DCQ, desethylchloro-quine; FMOH, Federal Ministry of Health; Hg, hemoglobin; PQ, primaquine; SPSS, Statistical Package for Social Sciences; WHO, World Health Organization.

\section{Acknowledgments}

We are pleased to pass our thanks to Mettu University for the financial support. Health offices of the districts owe the gratitude for their kind support throughout our stay. We also forward our appreciation to all health professional involved in the study. Last but not the least, we are grateful to the study participants for their kind cooperation and willingness.

\section{Author Contributions}

All authors conceived the study, carried out the field and laboratory works, were involved for analysis and interpretation of the data, and took part in drafting the manuscript. They critically read, revised for intellectually important content, gave the final approval of the version to be published, and agreed to be accountable for all aspects of the work.

\section{Disclosure}

The authors declare no competing interests in this work.

\section{References}

1. WHO. World malaria report. Geneva, Switzerland: World Health Organization fact sheet; 2013: Available from: https://www.who.int/ malaria/publications/world_malaria_report_2013/en/. Accessed June 20, 2020

2. O'Meara WP, Mangeni JN, Steketee R, Greenwood B. Changes in the burden of malaria in sub-Saharan Africa. Lancet Infect Dis. 2010;10 (8):545-555. doi:10.1016/S1473-3099(10)70096-7

3. Price RN, von Seidlein L, Valecha N, Nosten F, Baird JK, White NJ. Global extent of chloroquine-resistant Plasmodium vivax: a systematic review and meta-analysis. Lancet Infect Dis. 2014;14(10):982-991. doi:10.1016/S1473-3099(14)70855-2

4. Baird JK. Resistance to therapies for infection by Plasmodium vivax. Clin Microbiol Rev. 2009;22:508-534. doi:10.1128/CMR.00008-09

5. Dondorp AM, Nosten F, Yi P, et al. Artemisinin resistance in Plasmodium falciparum malaria. New Eng J Med. 2009;361(5):455467. doi:10.1056/NEJMoa0808859

6. Noedl H, Se Y, Schaecher K, Smith BL, Socheat D, Fukuda MM. Evidence of artemisinin-resistant malaria in Western Cambodia. New Eng J Med. 2008;359(24):2619-2620. doi:10.1056/NEJMc0805011
7. Price RN, Tjitra E, Guerra CA, Yeung S, White NJ, Anstey NM. Vivax malaria: neglected and not benign. Am J Trop Med Hyg. 2007;77(6_Suppl):79-87. doi:10.4269/ajtmh.2007.77.79

8. Rodriguez-Morales AJ, Benitez JA, Arria M. Malaria mortality in venezuela: focus on deaths due to Plasmodium vivax in children. $J$ Trop Pediatr. 2007;54(2):94-101. doi:10.1093/tropej/fmm074

9. Tjitra E, Anstey NM, Sugiarto P, et al. Multidrug-resistant Plasmodium vivax associated with severe and fatal malaria: a prospective study in Papua, Indonesia. PLoS Med. 2008;5(6):e128. doi:10.1371/journal.pmed.0050128

10. Deress T, Girma M. Plasmodium falciparum and Plasmodium vivax Prevalence in Ethiopia: A systematic Review and Meta Analysis. Malar J Treat. 2019;2019. doi:10.1155/2019/7065064.

11. Mendis K, Sina BJ, Marchesini PCR, Sina BJ. The neglected burden of Plasmodium vivax malaria. Am J Trop Med Hyg. 2001;64 (1_suppl):97-106. doi:10.4269/ajtmh.2001.64.97

12. Mueller I, Galinski MR, Baird JK, et al. Key gaps in the knowledge of Plasmodium vivax, a neglected human malaria parasite. Lancet Infect Dis. 2009;9(9):555-566. doi:10.1016/S1473-3099(09)70177-X

13. WHO. Guidelines for the treatment of malaria. Geneva; 2015. Available from: https://www.who.int/docs/default-source/documents/ publications/gmp/guidelines-for-the-treatment-of-malaria-eng. Accessed May 20, 2019.

14. Teka H, Petros B, Lawrence Y, et al. Chloroquine-resistant Plasmodium vivax malaria in Debre Zeit, Ethiopia. Malar J. 2008;7 (1):220. doi:10.1186/1475-2875-7-220

15. Ketema T, Bacha K, Birhanu T, Petros B. Chloroquine-resistant Plasmodium vivax malaria in Serbo town, Jimma zone, South-West Ethiopia. Malar J. 2009;8(1):177. doi:10.1186/1475-2875-8-177

16. Zema Z, Sulaiman S, Woldie M, Yesuf EA. Therapeutic efficacy of chloroquine in Plasmodium vivax at health centers in Jimma Town, South-West Ethiopia. J Health Med Nurs. 2016;23:13-19.

17. Assefa M, Eshetu T, Biruksew A. Therapeutic efficacy of chloroquine for the treatment of Plasmodium vivax malaria among outpatients at Hossana Health Care Centre, southern Ethiopia. Malar J. 2015;14 (1):458. doi:10.1186/s12936-015-0983-x

18. WHO. Methods for surveillance of antimalarial drug efficacy. Geneva, Switzerland; 2009. Available from: https://www.who.int/ malaria/publications/atoz/9789241597531/en/. Accessed September $10,2019$.

19. FMOH. National malaria guidelines. Fourth edition, Addis Ababa; 2017. Available from: https://www.humanitarianresponse.info/sites/ www.humanitarianresponse.info/files/documents/files/eth_national_ malaria_guidline_4th_edition.pdf. Accessed December 10, 2020.

20. WHO. Monitoring anti-malarial drug resistance Report of a WHO Consultation Geneva, Switzerland; 2002. Available from: https:// apps.who.int/iris/handle/10665/67590. Accessed June 23, 2018.

21. Daniel WW. Biostatistics: A Foundation for Analysis in the Health Sciences. 8th ed. New York: John Wiley \& Sons Inc; 2005.

22. Shrestha MB, Dunn L. The declaration of Helsinki on medical research involving human subjects: a review of seventh revision (Medical Education). J Nepal Health Res Counc. 2020;17(4):548552. doi:10.33314/jnhrc.v17i4.1042

23. Baird JK. Chloroquine resistance in Plasmodium vivax. Antimicr Agents Chemother. 2004;48(11):4075-4083. doi:10.1128/ AAC.48.11.4075-4083.2004

24. Getachew S, Thriemer K, Auburn S, et al. Chloroquine efficacy for Plasmodium vivax malaria treatment in southern Ethiopia. Malar J. 2015;14(1):525-533. doi:10.1186/s12936-015-1041-4 


\section{Publish your work in this journal}

Infection and Drug Resistance is an international, peer-reviewed openaccess journal that focuses on the optimal treatment of infection (bacterial, fungal and viral) and the development and institution of preventive strategies to minimize the development and spread of resistance. The journal is specifically concerned with the epidemiology of antibiotic resistance and the mechanisms of resistance development and diffusion in both hospitals and the community. The manuscript management system is completely online and includes a very quick and fair peerreview system, which is all easy to use. Visit http://www.dovepress.com/ testimonials.php to read real quotes from published authors. 